\title{
How Changing Prudence and Risk Aversion Affect Optimal Saving
}

\author{
CHRISTIAN BAUER \\ WOLFGANG BUCHHOLZ
}

CESIFO WORKING PAPER No. 2438

CATEgory 2: Public CHOICE

OCTOBER 2008

\footnotetext{
An electronic version of the paper may be downloaded

- from the SSRN website: Www.SSRN.com

- from the RePEc website: Www.RePEc.org

- from the CESifo website: www.CESifo-group.org/wp
} 


\title{
How Changing Prudence and Risk Aversion Affect Optimal Saving
}

\begin{abstract}
We show how optimal saving in a two-period model is affected when prudence and risk aversion of the underlying utility function change. Increasing prudence alone will induce higher savings only if, for certain combinations of the interest rate and the pure time discount rate, there is distributional neutrality between the two periods. Otherwise, changes of risk aversion that affect the distribution between the periods must also be taken into account.
\end{abstract}

JEL Code: D11, D81, E21, H43.

Keywords: prudence, risk aversion, saving, intergenerational distribution.

\author{
Christian Bauer \\ Department of Economics \\ University of Regensburg \\ 93040 Regensburg \\ Germany \\ christian.bauer@wiwi.uni-regensburg.de
}

\author{
Wolfgang Buchholz \\ Department of Economics \\ University of Regensburg \\ 93040 Regensburg \\ Germany
}

wolfgang.buchholz@wiwi.uni-regensburg.de

This version: $13 / 10 / 2008$ 


\section{Introduction}

A famous result in expected utility theory states that a mean preserving spread of risky exogenous future wealth leads to higher savings if the third derivative of the investor's von Neumann-Morgenstern utility function is positive (see Leland, 1968, Sandmo, 1970, and Drèze and Modigliani, 1972). Utility functions with this property thus reflect a specific precautionary savings motive and accordingly have been coined as "prudent" (Kimball, 1990). Just like different utility functions may show different degrees of risk aversion as indicated by the Arrow-Pratt measure, they may in a quite analogous way also show different degrees of absolute and relative prudence (see also Kimball, 1990, and the exposition in Gollier, 2001). Whereas in some cases a globally higher degree of prudence will increase savings, this assertion is not generally true (see, e.g., Menegatti, 2001, 2007, and Hau, 2002). In this paper we further explore, in the framework of the standard two period model with identical utility functions in both periods, how a higher degree of prudence affects the optimal level of savings. The findings of our analysis are ambiguous: If, through adequate combination of the exogenous interest rate and the pure time discount rate, some equal treatment of the two periods is ensured, higher prudence will induce higher savings. In other cases, the replacement of the utility functions typically has impacts on the distribution of consumption over time such that, in addition, changes of risk aversion have to be taken into account. If risk is low or the interest rate is high, the partial effect brought about by a change of risk aversion will dominate, and the change of prudence becomes irrelevant. Moreover, it can be shown that in the more general case with different utility functions in both periods, it cannot a priori be expected that criteria based only on changes in prudence and risk aversion will generate clear-cut effects on savings behavior.

\section{The Model}

Consider the standard optimal savings model under uncertainty when there are two periods, which we synonymously interpret as two subsequent generations. ${ }^{1}$ We first assume that the utility function is the same in the two periods 0 and 1 , such that the objective function, i.e. the social welfare function in the intergenerational case, is

$$
u\left(w_{0}-s\right)+\beta E u\left(\tilde{w}_{1}+\rho s\right)
$$

Here, $w_{0}$ denotes the given certain wealth in the first period, $\tilde{w}_{1}$ is the uncertain wealth in the second period and $s$ is the endogenous amount of savings such that the (safe) consumption in the earlier

\footnotetext{
${ }^{1}$ With this interpretation, our results also have some relevance for the problem of intergenerational distribution which is an important issue, e.g., in the current debate on global warming (see, e.g., Stern, 2006).
} 
period is $c_{0}=w_{0}-s$ and (risky) consumption in the latter period is $c_{1}=\tilde{w}_{1}+\rho s$. The von NeumannMorgenstern utility function $u\left(c_{i}\right)$ (with $i=1,2$ ) is assumed to be defined on $\mathbb{R}^{+}$and to be three times continuously differentiable with $u^{\prime}\left(c_{i}\right)>0, u^{\prime \prime}\left(c_{i}\right)<0$, and $u^{\prime \prime \prime}\left(c_{i}\right)>0$, i.e. it is strictly monotonically increasing in consumption $c$, strictly concave, and prudent.

The marginal rate of transformation $\rho$ between consumption in period 0 and 1 and the pure time discount factor $\beta$ are exogenously given by $\rho=1+r$ and $\beta=1 /(1+\delta)$ where $r$ is the interest rate and $\delta$ is the pure rate of time discount. We assume that maximizing (1) with respect to $s$ yields an interior solution $s_{u}^{*}$, which is characterized by the first order condition

$$
u^{\prime}\left(w_{0}-s_{u}^{*}\right)=\beta \rho E u^{\prime}\left(\tilde{w}_{1}+\rho s_{u}^{*}\right) .
$$

An important role in our analysis is played by the "precautionary equivalent wealth level" $\hat{w}_{1}=$ $\hat{w}_{1}\left(\rho s_{u}^{*}, u, \tilde{w}_{1}\right)$, which is defined as the certainty-equivalent of the wealth distribution under optimal savings $s_{u}^{*}$ in period 1 when $-u^{\prime}(c)$ is taken to be the utility function. Thus,

$$
u^{\prime}\left(\hat{w}_{1}\right)=E u^{\prime}\left(\tilde{w}_{1}+\rho s_{u}^{*}\right) .
$$

In general, the precautionary equivalent wealth level $\hat{w}_{1}$ is related to the well-known precautionary equivalent premium $\psi$ via $\hat{w}_{1}=E \tilde{w}_{1}+\rho s_{u}^{*}-\psi\left(\rho s_{u}^{*}, u, \tilde{w}_{1}\right)$ (see Kimball, 1990, and Gollier, 2001, 128).

The relation between $\hat{w}_{1}$ and consumption $w_{0}-s_{u}^{*}$ in period 0 then crucially depends on the size of $\beta \rho$. In particular,

$$
\beta \rho<1(=1,>1) \Rightarrow \frac{\hat{w}_{1}}{w_{0}-s_{u}^{*}}<1 \quad(=1,>1) .
$$

This assertion follows as (2) and (3) imply

$$
u^{\prime}\left(\hat{w}_{1}\right)=\frac{u^{\prime}\left(w_{0}-s_{u}^{*}\right)}{\beta \rho}
$$

and $u(c)$ is strictly concave.

We now analyze how optimal savings will change if the utility function $u(c)$ is substituted by another utility function $v(c)$.

\section{The Results}

We assume that the new utility function $v(c)$ has the same properties as the original utility function $u(c)$, i.e. that it is three times differentiable with $v^{\prime}(c)>0, v^{\prime \prime}(c)<0$, and $v^{\prime \prime \prime}(c)>0$. Furthermore, $v(c)$ is supposed to be more prudent than $u(c)$ according to the definition of Kimball (1990), i.e.

$$
-\frac{v^{\prime \prime \prime}(c)}{v^{\prime \prime}(v)}>-\frac{u^{\prime \prime \prime}(c)}{u^{\prime \prime}(c)}
$$


holds for all consumption levels $c>0$. Hence, if $v(c)$ is more prudent than $u(c)$ according to (6), the utility function $-v^{\prime}(c)$ is more risk averse than the utility function $-u^{\prime}(c)$. Together with the identity in (3), a standard result concerning changes of Arrow-Pratt risk aversion (see, e.g., Gollier, 2001, 21) then implies

$$
v^{\prime}\left(\hat{w}_{1}\right)<E v^{\prime}\left(\tilde{w}_{1}+\rho s_{u}^{*}\right) .
$$

This result can be used to show that in specific cases higher prudence will induce higher savings.

Proposition 1. If $\beta \rho$ is sufficiently close to 1, more prudence implies higher savings.

Proof. We first consider the case $\beta \rho=1$. Then, $\hat{w}_{1}=w_{0}-s_{u}^{*}$ from (4) such that (7) gives

$$
v^{\prime}\left(w_{0}-s_{u}^{*}\right)<E v^{\prime}\left(\tilde{w}_{1}+\rho s_{u}^{*}\right)
$$

Starting from (8) with $s=s_{u}^{*}$, it is a straightforward implication of the concavity of $v(c)$ that $s$ has to be increased to restore equality, i.e. to get

$$
v^{\prime}\left(w_{0}-s_{v}^{*}\right)=E v^{\prime}\left(\tilde{w}_{1}+\rho s_{v}^{*}\right)
$$

as the first order condition for optimal savings $s_{v}^{*}$ with the new utility function $v(c)$. Therefore, $s_{v}^{*}>s_{u}^{*}$ holds in the case $\beta \rho=1$ and then, from continuity, also if $\beta \rho$ is sufficiently close to 1 .

In general, however, higher prudence alone is not sufficient to provide unambiguous results on an increase in optimal savings. Rather, additional assumptions on an accompanying change of risk aversion are required. We then have two results on the change of optimal savings depending on whether $\beta \rho<1$ or $\beta \rho>1$.

Proposition 2. If $\beta \rho<1$, higher prudence combined with higher risk aversion implies higher savings.

Proof. If $v(c)$ is globally more risk averse according to Arrow-Pratt's standard definition, i.e. $-\frac{v^{\prime \prime}(c)}{v^{\prime}(c)}>$ $-\frac{u^{\prime \prime}(c)}{u^{\prime}(c)}$ holds for all $c>0$, the ratio of marginal utilities $\frac{v^{\prime}(c)}{u^{\prime}(c)}$ is decreasing in $c$. Since, in the case $\beta \rho<1$, (4) gives $\hat{w}_{1}<w_{0}-s_{u}^{*}$, then

$$
\frac{v^{\prime}\left(w_{0}-s_{u}^{*}\right)}{v^{\prime}\left(\hat{w}_{1}\right)}<\frac{u^{\prime}\left(w_{0}-s_{u}^{*}\right)}{u^{\prime}\left(\hat{w}_{1}\right)}=\beta \rho .
$$

From (10) and (7), i.e. higher prudence of $v(c)$, we get

$$
v^{\prime}\left(w_{0}-s_{u}^{*}\right)<\beta \rho E v^{\prime}\left(\tilde{w}_{1}+\rho s_{u}^{*}\right)
$$

A similar reasoning as at the end of the proof of Proposition 1 then shows $s_{v}^{*}>s_{u}^{*}$. 
Quite analogously, a result for the case $\beta \rho>1$ can be obtained.

Proposition 3. If $\beta \rho>1$, higher prudence combined with lower risk aversion implies higher savings.

Proof. If $v(c)$ has a lower risk aversion than $u(c), \frac{v^{\prime}(c)}{u^{\prime}(c)}$ is increasing in $c$. Since in the case $\beta \rho>1$ we have $\hat{w}_{1}>w_{0}-s_{u}^{*}$, condition (10) again holds. The proof then continues just like in the case of Proposition 2.

We now want to provide some intuitive explanation for these results, which should make it more transparent why savings behavior depends both on prudence and on risk aversion.

\section{The Interaction of Changes in Prudence and Risk Aversion: An Interpretation}

For an interpretation of the results derived in the previous section, we start with the case $\beta \rho=1$ in which $\beta$ and $\rho$ balance each other. Under the standard assumption that the economy is productive, i.e. $\rho>1$ holds, this advantage for the later generation is compensated by a positive pure time discount rate $\delta>0$, i.e. $\beta<1$, so as to avoid an unequal outcome and thus to ensure distributional neutrality. This is a classical justification for pure time preference that dates back to Böhm-Bawerk (1883)(see also, e.g., Arrow, 1999, and - clearly expressed but quite unnoticed - Rawls, 1972, 297-298). How smoothing of consumption across the two generations is brought about by $\beta \rho=1$ is particularly obvious in the special case when there is no wealth risk in the later period, i.e. if $\tilde{w}_{1}$ is non random. In this situation, $\beta \rho=1$ implies equal consumption levels for both generations. In the case where $\tilde{w}_{1}$ is a random variable, the distributional balance between the two generations manifests itself in the identity between consumption in period 0 and the size of the precautionary equivalent wealth level. Then, as described by Proposition 1, the savings level is only affected by changes in prudence since effects on intergenerational distribution are canceled out.

If, however, $\beta \rho \neq 1$, things look quite different because in this case, a change of the utility function not only exerts an influence on precautionary savings, but also on the distribution of consumption across generations. First, consider the case $\beta \rho<1$ in which the future generation is disadvantaged through a discount rate $\delta$ that is higher than the interest rate $r$, i.e. $\beta$ is smaller than $\rho$. In the benchmark case without wealth risk, the future generation then would have a lower level of consumption than the present generation. With uncertainty in wealth $\tilde{w}_{1}$ in period 1 , the precautionary equivalent 
wealth level is lower than consumption in period 1, i.e. $\hat{w}_{1}<w_{0}-\rho s_{u}^{*}$. Now, higher prudence still induces higher saving via the precautionary motive (as in the case $\beta \rho=1$ ) but, in addition, the effects on the intergenerational distribution that are implied by the replacement of the utility function have to be taken into account, as well. Since higher saving corresponds to a more equal intergenerational distribution in the case $\beta \rho<1$, the new utility function $v(c)$ must be more risk averse in order to ensure a higher level of optimal saving (see Proposition 2). ${ }^{2}$ In the other case with $\beta \rho>1$, it is the future generation that is privileged by the underlying combination of $\beta$ and $\rho$ which is reflected through $\hat{w}_{1}>w_{0}-\rho s_{u}^{*}$. To generate higher savings in this situation, the intergenerational distribution has to become less equal such that higher prudence must be combined with less risk aversion (see Proposition 3).

Considering general risk averse utility functions, there is no systematic relationship between changes of prudence and changes of risk aversion, ${ }^{3}$ which makes our results substantial. For specific classes of utility functions, however, increased prudence goes along with increased risk aversion such that there are opposing effects. Consider, as an example, the important case of isoelastic utility functions for which the constant elasticity of marginal utility is denoted by $\eta$. Further assume that the economy is productive, i.e. $\rho>1$, and that there is no pure time discount such that utility in both periods is given equal weight, i.e. $\beta=1$. An increase in risk aversion $\eta$ now leads to an increase in the degree of relative prudence which is $\eta+1$. Therefore, the negative impact on savings that then results from higher risk aversion via the consumption smoothing effect over time is counteracted by the precautionary effect that stems from higher prudence. This ambiguity has clearly been noted by Dasgupta (2008) in his comment on Stern (2006).

If future wealth is certain, i.e. $\tilde{w}_{1}=w_{1}$, only changes of risk aversion matter. Therefore, by continuity, for any given $u(c), \beta$, and $\rho$ with $\beta \rho<1$ and any utility function $v(c)$ that is more risk averse than $u(c)$, there always exists, irrespective of the prudence of $v(c)$, a random wealth distribution $\tilde{w}_{1}$ with $E \tilde{w}_{1}=w_{1}$ such that $s_{v}^{*}>s_{u}^{*}$. If $\beta \rho>1$, the analogous result hold for utility functions $v(c)$ that are less risk averse than $u(c)$. In this case, more saving is also compatible with lower prudence if future wealth is uncertain.

Concerning changes of prudence, another irrelevance result is obtained when, for given $u, \beta$, and $\rho$, the condition

$$
w_{0}-s_{u}^{*} \leq \underline{w}_{1}+\rho s_{u}^{*}
$$

\footnotetext{
${ }^{2}$ For some hints at the importance of risk aversion in this context see Ventura (2007).

${ }^{3}$ See Eeckhoudt and Schlesinger (1994) for examples of the independence and an analysis of some existing relationship between changes of prudence and risk aversion. Additional results on this are in Maggi, Magnani, and Menegatti (2006).
} 
holds for $s_{u}^{*}$ and $\underline{w}_{1}:=\min \tilde{w}_{1}$. Then, with optimal savings, wealth in period 1 in all states of the world is at least as high as wealth in period 0 . This clearly requires $\beta \rho>1$, and it is typically possible to generate the situation described in (12) by only decreasing $\rho$ strongly enough. ${ }^{4}$ Now, assume that $u(c)$ is replaced by any utility function $v(c)$ that is less risk averse than $u(c)$. Then, $h(c):=v^{\prime}(c) / u^{\prime}(c)$ is increasing in $c$, such that we get

$$
\begin{aligned}
v^{\prime}\left(w_{0}-s_{u}^{*}\right) & =h\left(w_{0}-s_{u}^{*}\right) u^{\prime}\left(w_{0}-s_{u}^{*}\right)=E h\left(w_{0}-s_{u}^{*}\right) u^{\prime}\left(\tilde{w}_{1}+\rho s_{u}^{*}\right) \\
& <E h\left(\tilde{w}_{1}+\rho s_{u}^{*}\right) u^{\prime}\left(\tilde{w}_{1}+\rho s_{u}^{*}\right)=E v^{\prime}\left(w_{0}+\rho s_{u}^{*}\right)
\end{aligned}
$$

By the standard argument already applied in the proofs of Propositions 1, 2, and 3 it then follows that $s_{v}^{*}>s_{u}^{*}$, independently of any assumption on the change in prudence. As we have started with a general utility function $u(c)$, these considerations also show that the potential irrelevance of changes in prudence for changes in savings is not a remote possibility, but rather a generic phenomenon.

\section{$5 \quad$ An Impossibility Result}

We finally consider the general case where the utility functions in both periods are different. By $u_{0}\left(c_{0}\right)$ we denote the utility function in the earlier, and by $u_{1}\left(c_{1}\right)$ that in the later period. Under otherwise unchanged assumptions, the objective function then becomes

$$
u_{0}\left(w_{0}-s\right)+\beta E u_{1}\left(\tilde{w}_{1}+\rho s\right)
$$

We now show that, given $u_{0}\left(c_{0}\right), \beta$, and $\rho$, it is not possible to characterize the class of period 1 utility functions $v_{1}\left(c_{1}\right)$ that induces higher savings than the original utility function $u_{1}\left(c_{1}\right)$ only by referring to their (absolute) degrees of risk aversion and prudence. This impossibility result follows from the following Proposition.

Proposition 4. Let $u_{1}\left(c_{1}\right)$ be replaced by some other utility function $v_{1}\left(c_{1}\right)$. Then, there always exists a utility function $\tilde{v}_{1}\left(c_{1}\right)$ which everywhere has the same degree of risk aversion and prudence as $v_{1}\left(c_{1}\right)$, but induces a lower amount of savings than $u_{1}\left(c_{1}\right)$.

\footnotetext{
${ }^{4}$ To see this, let $u^{\prime}(c)>0$ for all $c>0$. Now assume that $\rho s_{u}^{*}<M<\infty$ for all $\rho>0$. Then, from concavity $E u^{\prime}\left(\tilde{w}_{1}+\rho s_{u}^{*}\right)>E u^{\prime}\left(\tilde{w}_{1}+M\right)>0$ for all $\rho$ such that, for any $\beta>0, \lim _{\rho \rightarrow \infty} \beta \rho E u^{\prime}\left(\tilde{w}_{1}+\rho s_{u}^{*}\right)=\infty$. The supposed boundedness of $\rho s_{u}^{*}$, however, implies $\lim _{\rho \rightarrow \infty} s_{u}^{*}=0$, such that $\lim _{\rho \rightarrow \infty} u^{\prime}\left(w_{0}-s_{u}^{*}\right)=u^{\prime}\left(w_{0}\right)<\infty$, which is not compatible with the first order condition (2). Thus, $\lim _{\rho \rightarrow \infty}\left(\underline{w}_{1}+\rho s_{u}^{*}\right)=\lim _{\rho \rightarrow \infty} \rho s_{u}^{*}=\infty$. This implies that there must exist a $\tilde{\rho}$ such that $\underline{w}_{1}+\rho s_{u}^{*}>w_{0}>w_{0}-s_{u}^{*}$ for all $\rho>\tilde{\rho}$.
} 
Proof. Define $\tilde{v}_{1}\left(c_{1}\right)$ as $\tilde{v}_{1}\left(c_{1}\right):=\gamma v_{1}\left(c_{1}\right)$ for some constant $\gamma>0$. Thus, $\tilde{v}_{1}\left(c_{1}\right)$ clearly has the same degrees of risk aversion and prudence as $v_{1}\left(c_{1}\right)$. Now, choose $\gamma$ small enough such that

$$
u_{0}^{\prime}\left(w_{1}-s_{u_{0}, u_{1}}^{*}\right)>\beta E \gamma v_{1}^{\prime}\left(\tilde{w}_{1}+\rho s_{u_{0}, u_{1}}^{*}\right)=\beta E \tilde{v}_{1}^{\prime}\left(\tilde{w}_{1}+\rho s_{u}^{*}\right)
$$

where $s_{u_{0}, u_{1}}^{*}$ denotes optimal savings under the original combination $\left(u_{0}\left(c_{0}\right), u_{1}\left(c_{1}\right)\right)$ of utility functions. Then, again by the standard argument described in the proof of Proposition 1, savings must decrease when $u_{1}\left(c_{1}\right)$ is substituted by $\tilde{v}_{1}\left(c_{1}\right)$.

So we see that, because of a level effect, it cannot be expected in the general case that changes of risk aversion and/or prudence will provide sensible results on changes of savings behavior.

\section{Conclusion}

This paper has confirmed that only in rather limited cases changes in the degree of prudence of utility functions have unambiguous effects on optimal saving in the standard two period model. Only when there are identical utility functions in both periods and the underlying combination of the interest rate and the pure discount rate approximately give rise to distributional neutrality across the two periods, it is ensured that higher prudence induces higher savings. Otherwise, additional properties of the utility functions also play an important role. With identical utility functions in both periods, changes of risk aversion are also relevant when the intergenerational distribution is not balanced. Then, distributional effects that are not grasped by changing prudence but instead by changing risk aversion as a separate determinant become relevant for the saving decision. In general it is, depending on the given interest and pure time discount rate, well possible that the precautionary effect and the consumption smoothing effect over time that result from a change of the utility function either support or work against each other.

\section{Acknowledgments}

We thank Lutz Arnold, Christian Gollier, Harris Schlesinger, and Jan Schumacher for helpful comments and suggestions. 


\section{References}

Arrow, K. (1999): "Discounting and Intergenerational Equity," in Discounting, Morality, and Gaming, ed. by P. R. Portney, and J. P. Weyant. Resources for the Future, Washington, DC, 13-21.

Böhm-Bawerk, E. v. (1891): The Positive Theory of Capital. Translated by W. Smart, Stechert, New York, NY (originally published in German in 1888).

Dasgupta, P. (2008): "Discounting Climate Change," Journal of Risk and Uncertainty, forthcoming.

DrÈze, J., And F. Modigliani (1972): "Consumption Decisions under Uncertainty," Journal of Economic Theory, 5, 308-335.

Eeckhoudt, L., And H. Schlesinger (1994): "Increases in Prudence and Increases in Risk Aversion," Economics Letters, 45, 51-53.

Gollier, C. (2001): The Economics of Risk and Time. MIT Press, Cambridge, MA.

Hau, A. (2002): "Prudence, Intertemporal Substitution, and Savings under Uncertainty," Journal of Economics, 77, 35-52.

Kimball, M. (1990): "Precautionary Saving in the Large and in the Small," Econometrica, 58, 53-73.

Leland, H. (1968): "Saving and Uncertainty: The Precautionary Demand for Saving," Quarterly Journal of Economics, 82, 465-473.

Maggi, M., U. Magnani, and M. Menegatti (2006): "On the Relationship Between Absolute Prudence and Absolute Risk Aversion," Decisions in Economics and Finance, 29, 155-160.

Menegatti, M. (2001): "On the Conditions for Precautionary Saving," Journal of Economic Theory, 98, 189-193.

(2007): "A New Interpretation for the Precautionary Saving Motive: A Note," Journal of Economics, 92, 275-280.

Rawls, J. (1972): A Theory of Justice. Oxford University Press, Oxford, UK.

Sandmo, A. (1970): "The Effect of Uncertainty on Saving Decisions," Review of Economic Studies, $37,353-360$.

Stern, N. H. (2006): Stern Review on the Economics of Climate Change. Available online at http://www.hm-treasury.gov.uk. 
Ventura, L. (2007): “A Note on the Relevance of Prudence in Precautionary Saving," Economics Bulletin, 4, 1-11. 


\section{CESifo Working Paper Series}

for full list see www.cesifo-group.org/wp

(address: Poschingerstr. 5, 81679 Munich, Germany, office@cesifo.de)

2377 Inmaculada Martínez-Zarzoso, The Impact of Urbanization on $\mathrm{CO}_{2}$ Emissions: Evidence from Developing Countries, August 2008

2378 Brian Roberson and Dmitriy Kvasov, The Non-Constant-Sum Colonel Blotto Game, August 2008

2379 Ian Dew-Becker, How Much Sunlight Does it Take to Disinfect a Boardroom? A Short History of Executive Compensation Regulation, August 2008

2380 Cécile Aubert, Oliver Falck and Stephan Heblich, Subsidizing National Champions: An Evolutionary Perspective, August 2008

2381 Sebastian Buhai, Miguel Portela, Coen Teulings and Aico van Vuuren, Returns to Tenure or Seniority?, August 2008

2382 Erkki Koskela and Jan König, Flexible Outsourcing, Profit Sharing and Equilibrium Unemployment, August 2008

2383 Torberg Falch and Justina AV Fischer, Does a Generous Welfare State Crowd out Student Achievement? Panel Data Evidence from International Student Tests, September 2008

2384 Pedro Gomes and François Pouget, Corporate Tax Competition and the Decline of Public Investment, September 2008

2385 Marko Koethenbuerger, How Do Local Governments Decide on Public Policy in Fiscal Federalism? Tax vs. Expenditure Optimization, September 2008

2386 Ronald McKinnon and Gunther Schnabl, China's Exchange Rate Impasse and the Weak U.S. Dollar, September 2008

2387 Yan-Leung Cheung, Yin-Wong Cheung and Alan T.K. Wan, A High-Low Model of Daily Stock Price Ranges, September 2008

2388 Louis Eeckhoudt and Harris Schlesinger, Changes in Risk and the Demand for Saving, September 2008

2389 Carsten Hefeker and Blandine Zimmer, Uncertainty and Fiscal Policy in an Asymmetric Monetary Union, September 2008

2390 Jay Pil Choi and Byung-Cheol Kim, Net Neutrality and Investment Incentives, September 2008

2391 Marcel Gérard, Financing Bologna, the Internationally Mobile Students in European Higher Education, September 2008 
2392 Annette Alstadsæter and Knut Reidar Wangen, Corporations' Choice of Tax Regime when Transition Costs are Small and Income Shifting Potential is Large, September 2008

2393 António Afonso and Christophe Rault, 3-Step Analysis of Public Finances Sustainability: the Case of the European Union, September 2008

2394 Betsey Stevenson and Justin Wolfers, Economic Growth and Subjective Well-Being: Reassessing the Easterlin Paradox, September 2008

2395 Bernhard Eckwert and Itzhak Zilcha, Private Investment in Higher Education: Comparing Alternative Funding Schemes, September 2008

2396 Øystein Foros, Hans Jarle Kind and Jan Yngve Sand, Slotting Allowances and Manufacturers' Retail Sales Effort, September 2008

2397 Mohammad Reza Farzanegan, Illegal Trade in the Iranian Economy: Evidence from a Structural Model, September 2008

2398 Olivier Bos, Charity Auctions for the Happy Few, September 2008

2399 Robert S. Chirinko and Debdulal Mallick, The Marginal Product of Capital: A Persistent International Puzzle, September 2008

2400 Ben D'Exelle and Arno Riedl, Elite Capture, Political Voice and Exclusion from Aid: An Experimental Study, September 2008

2401 Torben M. Andersen and Joydeep Bhattacharya, On Myopia as Rationale for Social Security, September 2008

2402 Fabienne Llense, French CEO Compensations: What is the Cost of a Mandatory Upper Limit?, September 2008

2403 Valentina Bosetti, Carlo Carraro, Alessandra Sgobbi and Massimo Tavoni, Delayed Action and Uncertain Targets. How Much Will Climate Policy Cost?, September 2008

2404 Robert G. Chambers, Rolf Färe, Shawna Grosskopf and Michael Vardanyan, Generalized Quadratic Revenue Functions, September 2008

2405 Leonidas Enrique de la Rosa, Overconfidence in a Career-Concerns Setting, September 2008

2406 Marcus Drometer and Johannes Rincke, The Design of Political Institutions: Electoral Competition and the Choice of Ballot Access Restrictions in the United States, September 2008

2407 Markku Lanne and Helmut Lütkepohl, Stock Prices and Economic Fluctuations: A Markov Switching Structural Vector Autoregressive Analysis, September 2008 
2408 Thomas L. Brewer, International Energy Technology Transfers for Climate Change Mitigations, September 2008

2409 Alexander Kemnitz, Native Welfare Losses from High Skilled Immigration, September 2008

2410 Xavier Vives, Strategic Supply Function Competition with Private Information, September 2008

2411 Fabio Padovano and Roberto Ricciuti, The Political Competition-Economic Performance Puzzle: Evidence from the OECD Countries and the Italian Regions, September 2008

2412 Joan Costa-Font and Mireia Jofre-Bonet, Body Image and Food Disorders: Evidence from a Sample of European Women, September 2008

2413 Thorsten Upmann, Labour Unions - To Unite or to Separate?, October 2008

2414 Sascha O. Becker and Ludger Woessmann, Luther and the Girls: Religious Denomination and the Female Education Gap in $19^{\text {th }}$ Century Prussia, October 2008

2415 Florian Englmaier and Stephen Leider, Contractual and Organizational Structure with Reciprocal Agents, October 2008

2416 Vittorio Daniele and Ugo Marani, Organized Crime and Foreign Direct Investment: The Italian Case, October 2008

2417 Valentina Bosetti, Carlo Carraro, Alessandra Sgobbi and Massimo Tavoni, Modelling Economic Impacts of Alternative International Climate Policy Architectures. A Quantitative and Comparative Assessment of Architectures for Agreement, October 2008

2418 Paul De Grauwe, Animal Spirits and Monetary Policy, October 2008

2419 Guglielmo Maria Caporale, Christophe Rault, Robert Sova and Anamaria Sova, On the Bilateral Trade Effects of Free Trade Agreements between the EU-15 and the CEEC-4 Countries, October 2008

2420 Yin-Wong Cheung and Daniel Friedman, Speculative Attacks: A Laboratory Study in Continuous Time, October 2008

2421 Kamila Fialová and Ondřej Schneider, Labour Market Institutions and their Effect on Labour Market Performance in the New EU Member Countries, October 2008

2422 Alexander Ludwig and Michael Reiter, Sharing Demographic Risk - Who is Afraid of the Baby Bust?, October 2008

2423 Doina Maria Radulescu and Michael Stimmelmayr, The Welfare Loss from Differential Taxation of Sectors in Germany, October 2008 
2424 Nikolaus Wolf, Was Germany ever United? Evidence from Intra- and International Trade 1885 - 1933, October 2008

2425 Bruno S. Frey, David A. Savage and Benno Torgler, Noblesse Oblige? Determinants of Survival in a Life and Death Situation, October 2008

2426 Giovanni Facchini, Peri Silva and Gerald Willmann, The Customs Union Issue: Why do we Observe so few of them?, October 2008

2427 Wido Geis, Silke Uebelmesser and Martin Werding, Why go to France or Germany, if you could as well go to the UK or the US? Selective Features of Immigration to four major OECD Countries, October 2008

2428 Geeta Kingdon and Francis Teal, Teacher Unions, Teacher Pay and Student Performance in India: A Pupil Fixed Effects Approach, October 2008

2429 Andreas Haufler and Marco Runkel, Firms' Financial Choices and Thin Capitalization Rules under Corporate Tax Competition, October 2008

2430 Matz Dahlberg, Heléne Lundqvist and Eva Mörk, Intergovernmental Grants and Bureaucratic Power, October 2008

2431 Alfons J. Weichenrieder and Tina Klautke, Taxes and the Efficiency Costs of Capital Distortions, October 2008

2432 Andreas Knabe and Ronnie Schöb, Minimum Wage Incidence: The Case for Germany, October 2008

2433 Kurt R. Brekke and Odd Rune Straume, Pharmaceutical Patents: Incentives for R\&D or Marketing?, October 2008

2434 Scott Alan Carson, Geography, Insolation, and Institutional Change in $19^{\text {th }}$ Century African-American and White Stature in Southern States, October 2008

2435 Emilia Del Bono and Daniela Vuri, Job Mobility and the Gender Wage Gap in Italy, October 2008

2436 Marco Angrisani, Antonio Guarino, Steffen Huck and Nathan Larson, No-Trade in the Laboratory, October 2008

2437 Josse Delfgaauw and Robert Dur, Managerial Talent, Motivation, and Self-Selection into Public Management, October 2008

2438 Christian Bauer and Wolfgang Buchholz, How Changing Prudence and Risk Aversion Affect Optimal Saving, October 2008 